\title{
Bus Bay Performance and its Influence on the Capacity of Road Network in Dar Es Salaam
}

\author{
Nurdin K. Mushule \\ Department of Transportation and Geotechnical Engineering, \\ College of Engineering and Technology, University of Dar es Salaam Tanzania
}

Received 2012-04-17; Revised 2012-05-29; Accepted 2012-06-29

\begin{abstract}
One of major problems facing motorists in Dar es Salaam city today is congestion. Bus bays have a significant influence on the capacity of a roadway because they interfere with passing vehicles primarily when buses maneuver to pull into and out of bus bays. Bus bay stops will also interfere with vehicles movement if bus demand exceeds the bus bay capacity resulting in some buses waiting in the travel lane until the buses occupying the bay exit the bay. This paper presents the results of a study which was carried out to evaluate the bus bay performance and its influence on the capacity of the roadway network in the city of Dar es Salaam. The case study area covered 11 bus stops along Morogoro road from Ubungo to Magomeni Mapipa. Capacity of bus bays was studied using procedure outlined in the Transit Capacity and Quality of Service Manual of 2003. This enabled the researcher to determine parameters such as dwell times and clearance times which are major determinants of bus stop capacity. The results indicate that only $18 \%$ of the bus bay stops studied did not have adequate capacity to cater for the available demand. $9 \%$ did not have adequate capacity during peak hours but the capacity was adequate during off-peak hours. The remaining $73 \%$ of bus bay stops possess adequate capacity all the time. Although most bus bay stops studied possess adequate capacity, severe congestion was observed at these locations. This is due to erratic behavior of bus drivers who do not utilize the provided space for them to drop off and pick up passengers. Clearly, this is an area that requires more strict enforcement in order to ease the congestion problem in the city by operating the existing capacity more efficiently.
\end{abstract}

Keywords: Traffic Law Enforcement, Driver Behavior, Congestion, Dwell Times, Curb Lane, Motorists

\section{INTRODUCTION}

Bus bay type of bus stop is constructed and separated from travel lanes and off normal section of a roadway that provides for the pickup and discharge of passengers. This design is meant to allow through traffic to flow freely without the obstruction of stopped buses. Bus bays are provided primarily on high volume or high speed roadways, such as sub-urban arterial roads. Also bus bays are frequently constructed in heavy congested downtown and shopping areas where large numbers of passengers may board and alight.

Bus bays have been introduced in a lot of bus stops in Tanzania in general and Dar es Salaam in particular, especially where stopping buses without bays would seriously block traffic stream. However, based on some observations, buses in bus bays do not stop closely at curbs. This causes great inconvenience to the boarding and alighting passengers due to big gaps between buses and curbs. There might be several reasons why buses do not stop closely at curbs including technical and psychological issues as well as traffic condition. This situation can be alleviated by providing properly designed bus bays (Nakamura et al., 2005).

One of major problems facing motorists in Dar es Salaam city today is congestion. Traffic congestion at bus bay bus stops in Dar es Salaam is on the rise due to increasing private automobiles on the roadway competing with public transport for the limited roadway space. In this regard, commuters waste a lot of time at bus stops as well as in the bus in order to get to their destinations. Highway Capacity Manual 2000 (TRB, 2000) presents some findings about the influence of bus stops on capacity when buses pull in and out of bus 
stops. The manual considers the number of buses per hour at each bus stop and the average bus stopping time (average bus dwell time). However, studies of bus bays' impact on capacity of curb lanes are found to be very few. A recent study by Kwami et al. (2009) investigated the quantitative impact of bus bays on curb lanes capacity of roadways in Beijing. In addition, $\mathrm{Gu}$ et al. (2010) examined the maximal rates that buses can discharge from bus stops. They found out that variation in bus service time tend to diminish stop capacity.

Intersections and Bus stops are bottlenecks in the highway networks. Ibrahim et al. (2008) studied the performance of signalised junctions with digital countdown display in Malaysia.

This paper presents the results of a study carried out to evaluate the bus bay performance and its impact on the capacity of roadways in Dar es Salaam city.

\section{MATERIALS AND METHODS}

\subsection{Approach}

The study presented in this paper covered one of the congested roads in Dar es Salaam city. A total of 11 bus bay stops were studied during different times of the day namely; morning peak, off-peak and evening peak. At each stop and at different times of the day, the study determined parameters such as dwell times, clearance times, dwell time variability and failure rate. These parameters were used to calculate the capacity of each bus bay stop.

In addition, bus arrival frequency was studied simultenously at the same bus bay stops and same time. This was done by simply counting the buses that arrived within 15 min period. Subsequently, The maximum flow rate was then determined by considering the highest number of buses which arrived in any 15 min duration converted into equivalent hourly rate.

Finally, for each bus stop and at different times of the day, the maximum flow rate was then compared to the bus bay capacity in order to determine whether the bus stop was capable of catering for the demand at any given time of the day.

Subsequent sections discuss the above parameters in detail and how they were determined in this study.

\subsection{Capacity of Bus Bays}

Capacity of bus bays has a great impact on the performance of transit operation. Bus bay stops will interfere with vehicles movement if bus demand exceeds the bus bay capacity resulting in some buses waiting in the travel lane until the buses occupying the bay exit the bay. In some cases, buses can block the curbside lane during their bay occupancy period if they do not fit completely within the bay due to reduced width of available bay or due to erratic behavior of drivers.
The loading area capacity of the bus stop (number of buses per berth per hour) can be estimated using equation 1 :

$$
\mathrm{Q}_{\mathrm{b}}=\frac{3,600\left(\frac{\mathrm{g}}{\mathrm{C}}\right)}{\mathrm{t}_{\mathrm{c}}+\left(\frac{\mathrm{g}}{\mathrm{C}}\right) \mathrm{t}_{\mathrm{d}}+\mathrm{Z}_{\mathrm{a}} \mathrm{C}_{\mathrm{v}} \mathrm{t}_{\mathrm{d}}}
$$

Where:

$\mathrm{Q}_{\mathrm{b}}=$ Capacity of bus stop/berth [bus/h];

$\frac{\mathrm{g}}{\mathrm{c}}=$ Effective green time per cycle (1.0 for a stop not at a signalized intersection)

$\mathrm{T}_{\mathrm{c}}=$ Clearance time $(\mathrm{s})$;

$\mathrm{T}_{\mathrm{d}}=$ Average dwell time (s)

$Z_{\mathrm{a}}=$ One-tail normal variate corresponding to probability that queues will form behind bus stop

$\mathrm{C}_{\mathrm{y}}=$ Coefficient of variation of dwell times

\subsection{Dwell Time}

The passenger demand volumes and passenger service times are key to determining dwell times. Dwell time represents a significant portion of bus operating time and contributes to its variability. Dwell times may be governed by boarding demand, alighting demand, or total interchanging passenger demand (i.e. at a major transfer point). Although dwell time is highly correlated with the number of passengers boarding and alighting, there are also other factors such as crowding, fare type and bus design that may affect it. These factors may strongly influence the effectiveness of different strategies used to improve bus service.

In this regard, according to TRB (2003), there are six main influences on dwell time. Two relate to passenger demand while the rest relate to passenger service time. These influences are:

\subsection{Passenger Demand and Loading}

The number of people boarding and alighting through the highest-volume door determines how long it will take to serve all passengers. If standees are present on a transit vehicle as it arrives at a stop, or if all seats are filled as passengers board, service times will be higher than normal because of congestion in the vehicle.

\subsection{Stop and Station Spacing}

The fewer the stops along a route, the greater the number of passengers boarding at each stop. A balance must be found between too few stops and too many. Too few stops increase both the distance riders must walk to gain access to transit and the amount of time a vehicle occupies a loading area. Too many stops reduce overall travel speeds due to the time lost in accelerating and decelerating as well as waiting at traffic signals because stops were made. 


\subsection{Fare Payment Procedure}

The amount of time passengers spend paying fares is a major factor in the total time for passenger boarding. This time can be reduced by minimizing the number of bills and coins required to pay a fare; encouraging the use of prepaid tickets, tokens, passes, or smart cards; using a proof-of-payment fare collection system; or collecting fares before boarding. Besides eliminating the time required for each passenger to pay a fare onboard, proof-of-payment and paid-fare waiting-area collection systems allow an even distribution of boarding passengers among the vehicle doors, rather than concentrating them at a single door.

\subsection{Vehicle Types}

Low-floor buses decrease passenger service time by eliminating needs to ascend and descend steps. This particularly applies to routes frequently used by the elderly, persons with disabilities, or persons with strollers or bulky carry-on items. Wide doors also allow more passengers to board and alight simultaneously.

\subsection{On-Board Circulation}

Encouraging people to exit via the rear doors of buses with more than one door decreases passenger congestion at the front door and reduces passenger service times.

\subsection{Wheel Chair and Bicycle Boarding}

Dwell time also can be affected by the time to board and disembark passengers in wheelchairs and for bicyclists to load and unload bicycles onto a busmounted bicycle rack.

According to TRB (2000). Average dwell time is given by equation 2 :

$\mathrm{T}_{\mathrm{d}}=\mathrm{P}_{\mathrm{a}} \mathrm{T}_{\mathrm{a}}+\mathrm{P}_{\mathrm{b}} \mathrm{T}_{\mathrm{b}}+\mathrm{T}_{\mathrm{oc}}$

Where:

$\mathrm{T}_{\mathrm{d}}=\quad$ Average dwell times (s)

$\mathrm{P}_{\mathrm{a}}=$ Alighting passengers per bus through the busiest door during peak $15 \mathrm{~min}(\mathrm{p})$

$\mathrm{T}_{\mathrm{a}}=\quad$ Alighting passenger service time $(\mathrm{s} / \mathrm{p})$

$\mathrm{P}_{\mathrm{b}}=$ Boarding passengers per bus through the busiest door during peak $15 \mathrm{~min}(\mathrm{p})$

$\mathrm{T}_{\mathrm{b}}=$ Boarding passenger service time ( $\mathrm{s} / \mathrm{p}$ )

$\mathrm{T}_{\mathrm{oc}}=\quad$ Door opening and closing times (s)

It has to be mentioned here that just as dwell times are key to determining capacity; passenger demand volumes and passenger service times are key to determining dwell times. In all cases, dwell time is proportionate to the boarding and alighting volumes times the service time per passenger. Dwell time also can influence transit operator's service costs: if average vehicle speeds can increase by reducing dwell time and if the cumulative change exceeds the route headway, then fewer vehicles may be required to provide the same service frequency.

\subsection{Estimating Dwell Time}

Dwell times can be estimated using one of the following methods (TRB, 2003):

- Field measurements-best for evaluating and existing bus route

- Default values-suitable for future planning when reliable estimates of future passenger boarding and alighting volumes are unavailable

- Calculation-suitable for estimating when passenger boarding and alighting counts or estimates are available

\subsection{Dwell Time Variability}

Naturally, depending on the fluctuation of passengers at the stop and other factors that affect dwell time, dwell time will differ between one bus and another. The effect of variability in bus dwell times on the capacity is reflected by the coefficient of variation of dwell times $\left(\mathrm{C}_{\mathrm{v}}\right)$.

The coefficient of variation of dwell times $\left(\mathrm{C}_{\mathrm{v}}\right)$ is given by equation 3 :

$\mathrm{Cv}=\delta \mathrm{d} / \mathrm{Td}$

Where:

$\mathrm{C}_{\mathrm{v}}=$ Coefficient of variation of dwell times

$\delta_{\mathrm{d}}=$ Standard deviation of dwell times

$\mathrm{T}_{\mathrm{d}}=$ Average dwell time (sec)

\subsection{Clearance Time}

Once a bus closes its doors and prepares to depart a stop, there is an additional period of time, known as the clearance time, when the loading area is not yet available for use by the next bus. Part of this time is fixed, consisting of the time for a bus to start up and travel its own length, clearing the stop.

Table 1. Value of $Z$ for different failure rates

\begin{tabular}{lll}
\hline $\mathrm{S} / \mathrm{N}$ & Failure rate $(\%)$ & $\mathrm{Z}$ \\
\hline 1 & 1.000 & 2.330 \\
2 & 2.500 & 1.960 \\
3 & 5.000 & 1.645 \\
4 & 7.500 & 1.440 \\
5 & 10.00 & 1.280 \\
6 & 15.00 & 1.040 \\
7 & 20.00 & 0.840 \\
8 & 25.00 & 0.675 \\
9 & 30.00 & 0.525 \\
10 & 50.00 & 0.000 \\
\hline
\end{tabular}

Source: TRB (2003) 
Table 2. Efficiency of multiple linear bus stop loading areas

\begin{tabular}{lllll}
\hline & On-line stations & Off-line stations & No. of cumulative \\
Berth & $-\begin{array}{ll}\text { Efficiency } \\
\text { no) }\end{array}$ & $\begin{array}{l}\text { No. of cumulative } \\
\text { effective berths }\end{array}$ & $\begin{array}{l}\text { Efficiency } \\
\mathbf{( \% )}\end{array}$ \\
\hline 1 & 100 & 1.00 & 100 & 1.000 \\
2 & 750 & 1.75 & 850 & 1.850 \\
3 & 500 & 2.25 & 650 & 2.600 \\
4 & 200 & 2.45 & 500 & 3.250 \\
5 & 500 & 2.50 & & 3.750 \\
\hline
\end{tabular}

Source: TRB (2000)

When buses stop in the traffic lane (on-line), this is the only component of clearance time. When buses stop out of traffic (off-line), there is another component to clearance time: the time required for a suitable gap in traffic to allow the bus to re-enter the street. This reentry delay depends on the traffic volume in the curb lane and increases as traffic volumes increase. The delay also depends on the influence of upstream traffic signals, which may create long gaps in traffic, followed by periods of time when a constant stream of cars passes the stop. Some agencies have laws requiring motorists to yield to buses re-entering a roadway; depending on how well motorists comply with these laws; the re-entry delay can be reduced or even eliminated (TRB, 2003). Many transit agencies avoid using off-line stops on busy streets in order to avoid this re-entry delay. However, many roadway agencies, prefer off-line stops to avoid delays to other traffic and to reduce the potential for rear-end collisions between other vehicles and stopped buses.

\subsection{Passenger Service Time}

This is the duration from when the door is opened to allow passengers to board and alight up to the time the door is closed and vehicle starts leaving from the loading area.

\subsection{Failure Rate}

The probability that a queue of buses will not form behind a bus stop can be derived from basic statistics. Za represents the area under one tail of the normal curve beyond the acceptable levels of a probability that queue will form at a bus stop. The value of $\mathrm{Z}$ corresponding to different failure rates are shown in Table 1.

According to TRB (2003), capacity is effectively reached at a failure rate of $25 \%$. Mathematically, capacity would be maximized at $50 \%$ failure rate. However, this requires precise control of bus headways, with the only variable being the passenger boarding volume on a given bus.

This situation is not only difficult to achieve in practice, but bus headways are never controlled in Dar es Salaam.

Highway Capacity Manual 2000 (TRB, 2000) suggests the following typical values:

- CBD stops: $Z_{\mathrm{a}}$ values of 1.440 down to 1.040 which result into probabilities of $7.5-15 \%$, respectively, that queues will develop
- Outlying stops: $A Z_{a}$ value of 1.960 should be used which results in queues beyond bus stops only $2.5 \%$ of the time

Bus Capacity of loading area is dependent on dwell time, clearance time, dwell time variability and failure rate. The combination of dwell time and clearance time gives the average amount of time an individual bus occupies the loading area. The combination of dwell time variability and design failure rate provides an additional margin of time to ensure that most buses will be able to immediately use the loading area upon arriving.

\subsection{Loading Area use Efficiency}

The bus stop vehicle capacity equals the number of loading areas times the vehicle capacity of each loading area if buses are able to maneuver in and out of the loading areas independently of other buses. However, it is not likely that the loading positions will be equally used, or that the passengers will be distributed equally among loading positions. Moreover, buses will be delayed in entering and leaving a berth by buses in adjacent loading area. According to the Transit Capacity and Quality of Service Manual (TRB, 2003) four types of bus berths are typically applied. These are linear, saw tooth, angular and drive-through. Linear berths operate in series and are less efficient than other types. Highway Capacity manual 2000 suggets berth efficiency factors as shown in Table 2.

Table 2 suggests that five "off-line" positions could have a maximum efficiency of as low as 3.75 berths.

\section{16. Bus Demand Estimation}

The bus arrival frequency is determined during 15 min interval within an hour. This is simply the counting of the buses that arrive within that 15 min period. The maximum flow rate is the highest number of buses which arrive in any 15 min duration converted into equivalent hourly rate. As discussed earlier, bus demand was compared to the bus bay capacity in order to determine whether the bus stop was capable of catering for the demand.

\section{RESULTS}

Dwell times and clearance times were studied at 11 bus bay stops, from Ubungo to Magomeni, during different times of the day. 
Nurdin K. Mushule / American Journal of Engineering and Applied Sciences 5 (2) (2012) 107-113

$\underline{\text { Table 3. Average dwell times and clearance times }}$

\begin{tabular}{|c|c|c|c|c|c|c|}
\hline $\mathrm{S} / \mathrm{N}$ & $\begin{array}{l}\text { Name of } \\
\text { Stop }\end{array}$ & $\begin{array}{l}\text { Time of } \\
\text { the day }\end{array}$ & $\begin{array}{l}\text { Average dwell } \\
\text { Time [sec] }\end{array}$ & $\begin{array}{l}\text { Coefficient } \\
\text { of Variation }\end{array}$ & $\begin{array}{l}\text { Average clearance } \\
\text { Times [sec] }\end{array}$ & $\begin{array}{l}\text { Capacity per } \\
\text { berth [bus/hr] }\end{array}$ \\
\hline \multirow[t]{3}{*}{1} & Ubungo & am peak & 073.060 & 0.81 & 18.760 & 17 \\
\hline & & off peak & 153.820 & 0.96 & 10.240 & 80 \\
\hline & & pm peak & 119.320 & 0.87 & 17.170 & 11 \\
\hline \multirow[t]{3}{*}{2} & Shekilango & am peak & 027.600 & 0.73 & 15.670 & 43 \\
\hline & & off peak & 053.420 & 0.45 & 08.980 & 33 \\
\hline & & pm peak & 026.670 & 0.69 & 12.130 & 48 \\
\hline \multirow[t]{3}{*}{3} & Urafiki & am peak & 021.420 & 0.54 & 16.510 & 59 \\
\hline & & off peak & 048.900 & 0.48 & 09.210 & 35 \\
\hline & & pm peak & 021.240 & 0.68 & 14.450 & 56 \\
\hline \multirow[t]{3}{*}{4} & Mahakama ya Ndizi & am peak & 032.450 & 0.55 & 15.610 & 43 \\
\hline & & off peak & 063.410 & 0.61 & 12.560 & 24 \\
\hline & & pm peak & 031.360 & 0.59 & 17.650 & 42 \\
\hline \multirow[t]{3}{*}{5} & Tip Тор & am peak & 021.860 & 0.87 & 18.760 & 46 \\
\hline & & off peak & 044.780 & 0.76 & 08.990 & 30 \\
\hline & & pm peak & 019.810 & 0.67 & 13.310 & 61 \\
\hline \multirow[t]{3}{*}{6} & Darajani & am peak & 023.140 & 0.51 & 21.340 & 53 \\
\hline & & off peak & 032.150 & 0.65 & 09.560 & 44 \\
\hline & & pm peak & 019.870 & 0.88 & 22.230 & 47 \\
\hline \multirow[t]{3}{*}{7} & Bakhresa & am peak & 027.050 & 0.98 & 16.130 & 38 \\
\hline & & off peak & 031.270 & 0.75 & 08.620 & 42 \\
\hline & & pm peak & 026.790 & 0.87 & 16.760 & 40 \\
\hline \multirow[t]{3}{*}{8} & Argentina & am peak & 025.450 & 0.77 & 17.770 & 44 \\
\hline & & off peak & 042.170 & 0.65 & 08.970 & 34 \\
\hline & & pm peak & 020.640 & 0.56 & 16.780 & 60 \\
\hline \multirow[t]{3}{*}{9} & Kagera & am peak & 025.730 & 0.59 & 18.130 & 49 \\
\hline & & off peak & 039.810 & 0.88 & 11.230 & 30 \\
\hline & & pm peak & 024.130 & 0.75 & 19.870 & 45 \\
\hline \multirow[t]{3}{*}{10} & Mwembechai & am peak & 024.940 & 0.87 & 17.280 & 42 \\
\hline & & off peak & 043.250 & 0.67 & 07.260 & 34 \\
\hline & & pm peak & 021.860 & 0.54 & 21.130 & 54 \\
\hline \multirow[t]{3}{*}{11} & Usalama & am peak & 031.610 & 0.78 & 23.170 & 35 \\
\hline & & off peak & 048.960 & 0.49 & 12.190 & 33 \\
\hline & & pm peak & 035.670 & 0.87 & 21.190 & 31 \\
\hline
\end{tabular}

Table 4. Capacity of bus bay stops at different times of the day

\begin{tabular}{|c|c|c|c|c|c|c|c|c|}
\hline $\mathrm{S} / \mathrm{N}$ & $\begin{array}{l}\text { Name } \\
\text { of stop }\end{array}$ & & $\begin{array}{l}\text { Capacity per } \\
\text { berth [bus/hr] }\end{array}$ & $\begin{array}{l}\text { No. of } \\
\text { loading areas } 1\end{array}$ & $\begin{array}{l}\text { No. of } \\
\text { effective berths }\end{array}$ & $\begin{array}{l}\text { Capacity of } \\
\text { stop [bus/hr] }\end{array}$ & $\begin{array}{l}\text { Bus arrival } \\
\text { rate [bus/hr] }\end{array}$ & $\begin{array}{l}\text { Max. flow } \\
\text { rate [bus/hr] }\end{array}$ \\
\hline \multirow[t]{3}{*}{1} & Ubungo & am peak & 17 & 5 & 3.75 & 650 & 153 & 168 \\
\hline & & off peak & 80 & 5 & 3.75 & 300 & 770 & 880 \\
\hline & & pm peak & 11 & 5 & 3.75 & 400 & 124 & 136 \\
\hline \multirow[t]{3}{*}{2} & Shekilango & am peak & 43 & 4 & 3.25 & 141 & 102 & 128 \\
\hline & & Off peak & 33 & 4 & 3.25 & 107 & 790 & 100 \\
\hline & & pm peak & 48 & 4 & 3.25 & 156 & 920 & 132 \\
\hline \multirow[t]{3}{*}{3} & Urafiki & am peak & 59 & 3 & 2.60 & 154 & 137 & 152 \\
\hline & & off peak & 35 & 3 & 2.60 & 900 & 680 & 760 \\
\hline & & pm peak & 56 & 3 & 2.60 & 146 & 123 & 136 \\
\hline \multirow[t]{3}{*}{4} & Mahakama & am peak & 43 & 4 & 3.25 & 141 & 135 & 152 \\
\hline & ya Ndizi & off peak & 24 & 4 & 3.25 & 770 & 770 & 840 \\
\hline & & pm peak & 42 & 4 & 3.25 & 137 & 129 & 148 \\
\hline \multirow[t]{3}{*}{5} & Tip Top & am peak & 46 & 4 & 3.25 & 150 & 132 & 144 \\
\hline & & off peak & 30 & 4 & 3.25 & 970 & 780 & 920 \\
\hline & & pm peak & 61 & 4 & 3.25 & 198 & 143 & 156 \\
\hline \multirow[t]{3}{*}{6} & Darajani & am peak & 53 & 5 & 3.75 & 200 & 152 & 168 \\
\hline & & off peak & 44 & 5 & 3.75 & 163 & 570 & 640 \\
\hline & & pm peak & 47 & 5 & 3.75 & 177 & 159 & 172 \\
\hline \multirow[t]{3}{*}{7} & Bakhresa & am peak & 38 & 5 & 3.75 & 142 & 128 & 136 \\
\hline & & off peak & 42 & 5 & 3.75 & 157 & 720 & 800 \\
\hline & & pm peak & 40 & 5 & 3.75 & 151 & 129 & 144 \\
\hline \multirow[t]{3}{*}{8} & Argentina & am peak & 44 & 4 & 3.25 & 143 & 102 & 116 \\
\hline & & off peak & 34 & 4 & 3.25 & 112 & 620 & 760 \\
\hline & & pm peak & 60 & 4 & 3.25 & 195 & 165 & 172 \\
\hline \multirow[t]{3}{*}{9} & Kagera & am peak & 49 & 4 & 3.25 & 159 & 142 & 156 \\
\hline & & off peak & 30 & 4 & 3.25 & 980 & 600 & 680 \\
\hline & & pm peak & 45 & 4 & 3.25 & 147 & 123 & 144 \\
\hline \multirow[t]{3}{*}{10} & Mwembechai & am peak & 42 & 4 & 3.25 & 138 & 121 & 132 \\
\hline & & off peak & 34 & 4 & 3.25 & 109 & 790 & 880 \\
\hline & & pm peak & 54 & 4 & 3.25 & 177 & 161 & 172 \\
\hline \multirow[t]{3}{*}{11} & Usalama & am peak & 35 & 4 & 3.25 & 113 & 139 & 152 \\
\hline & & off peak & 33 & 4 & 3.25 & 108 & 590 & 720 \\
\hline & & pm peak & 31 & 4 & 3.25 & 990 & 166 & 188 \\
\hline
\end{tabular}

${ }^{1}$ Number of buses occupying the stop at the same; ${ }^{2}$ Refer Table 2 
At all these stops, buses are required to stop out of traffic (off-line). The studies were carried out during morning peak hours, off peak hours and evening peak hours. Direct field measurement procedure, as outlined in the Transit Capacity and Quality of Service Manual (TRB, 2003), was adopted in this study. The results of average dwell times and their coefficient of variation as well as clearance times are presented in Table 3. As can be seen from Table 3, average dwell times range from 21.24 to as high as 153.82 sec with coefficient of variation ranging from 0.45-0.98. The results indicate that average dwell times are generally higher during off-peak hours because drivers spend more time at bus stops waiting for passengers.

In addition, average clearance times range from 7.26$23.17 \mathrm{sec}$. Average clearance times are generally shorter during off-peak hours because of shorter re-entry delay due to lower traffic volume on the curb lane.
Furthermore, bus arrival rates and maximum flow rates at each bus bay stop were studied. The results are as indicated in Table 4 . The results indicate that maximum flow rates range from 72-172 buses per hour. Generally the maximum flow rates are less during off-peak hours.

\section{DISCUSSION}

The comparison of capacity of each bus bay stop against the observed demand (maximum flow rate) is given and discussed in Table $\mathbf{5}$ and the summary is given in Table 6. The results indicate that most bus bay stops (73\% during peak hours and $82 \%$ during off-peak hours) possess adequate capacity to cater for the observed demand. In most cases, dwell times are affected by high passenger demand during peak hours. During off peak hours drivers spend a lot of time waiting for passengers.

Table 5. Capacity of bus bays against demand

\begin{tabular}{|c|c|c|c|c|c|}
\hline $\mathrm{S} / \mathrm{N}$ & $\begin{array}{l}\text { Name of } \\
\text { Stop }\end{array}$ & & $\begin{array}{l}\text { Capacity of } \\
\text { Stop [bus/hr] }\end{array}$ & $\begin{array}{l}\text { Maximum flow } \\
\text { Rate [bus/hr] }\end{array}$ & Remarks \\
\hline \multirow[t]{3}{*}{1} & Ubungo & am peak & 65 & 168 & Inadequate capacity due to high values of dwell time as indicated in Table \\
\hline & & off peak & 30 & 88 & 1. Dwell times are affected by passenger demand. \\
\hline & & pm peak & 40 & 136 & \\
\hline \multirow[t]{3}{*}{2} & Shekilango & am peak & 141 & 128 & Adequate capacity to cater for the observed demand. Sometimes the dwell \\
\hline & & off peak & 107 & 100 & time is prolonged because drivers spend more time for passengers. \\
\hline & & pm peak & 156 & 132 & \\
\hline \multirow[t]{3}{*}{3} & Urafiki & am peak & 154 & 152 & Adequate capacity to cater for the observed demand passenger \\
\hline & & off peak & 90 & 76 & demand is low and hence short dwell time. Sometimes the dwell time is \\
\hline & & pm peak & 146 & 136 & prolonged because drivers spend more time waiting for passengers. \\
\hline \multirow[t]{3}{*}{4} & Mahakama & am peak & 141 & 152 & Inadequate capacity due to socio-economic activities conducted on the \\
\hline & ya Ndizi & off peak & 77 & 84 & curb. These interfere with boarding and alighting of passengers hence \\
\hline & & pm peak & 137 & 148 & $\begin{array}{l}\text { increasing dwell time. In addition, the cross walk is located immediately } \\
\text { after the stop. }\end{array}$ \\
\hline \multirow[t]{3}{*}{5} & Tip Top & am peak & 150 & 144 & Adequate capacity of the bus bay. However, congestion was observed \\
\hline & & off peak & 97 & 92 & due inappropriate use of the bay by the drivers. \\
\hline & & pm peak & 198 & 156 & \\
\hline \multirow[t]{3}{*}{6} & Darajani & am peak & 200 & 168 & Adequate capacity of the bus bay. However, trucks also use this area \\
\hline & & off peak & 163 & 64 & reducing space for buses to pick and drop passengers. \\
\hline & & pm peak & 177 & 172 & \\
\hline 7 & Bakhresa & am peak & 142 & 136 & $\begin{array}{l}\text { Adequate capacity to cater for the observed demand. Passenger demand } \\
\text { was low and hence short dwell time. Sometimes the dwell time is }\end{array}$ \\
\hline & & & & & prolonged because drivers spend more time waiting for passengers. \\
\hline \multirow[t]{3}{*}{8} & Argentina & am peak & 143 & 116 & Adequate capacity to cater for the observed demand. However, at times, \\
\hline & & off peak & 112 & 76 & taxis park on the curb side affecting the effectiveness of the stop. \\
\hline & & pm peak & 195 & 172 & \\
\hline \multirow[t]{3}{*}{9} & Kagera & am peak & 159 & 156 & Adequate capacity to cater for the observed demand. Passenger demand \\
\hline & & off peak & 98 & 68 & is low and hence short dwell time. Sometimes the dwell time is \\
\hline & & pm peak & 147 & 144 & prolonged because drivers spend more time waiting for passengers. \\
\hline \multirow[t]{3}{*}{10} & Mwembechai & am peak & 138 & 132 & Adequate capacity for the observed demand. Passenger demand is low \\
\hline & & off peak & 109 & 88 & and hence short dwell time. Sometimes the dwell time is prolonged \\
\hline & & pm peak & 177 & 172 & because drivers spend more time waiting for passengers. \\
\hline \multirow[t]{3}{*}{11} & Usalama & am peak & 113 & 152 & Adequate capacity only during off peak hour. High demand of alighting \\
\hline & & off peak & 108 & 72 & and boarding passengers results into longer dwell times during peak \\
\hline & & pm peak & 99 & 188 & hours. \\
\hline
\end{tabular}

Table 6. Summary of capacity of bus bay stops

\begin{tabular}{lllll}
\hline & Adequate capacity & Inadequate capacity & \\
Time of the day & - No. of Stops & $(\%)$ & No. of Stops & (\%) \\
\hline am peak & 8 & 73 & 3 & 27 \\
off peak & 9 & 82 & 2 & 18 \\
pm peak & 8 & 73 & 3 & 27 \\
\hline
\end{tabular}


The results of this study clearly indicate that there is also a need to re-examine the current practice and operate the existing capacity more efficiently and get more out of what we have. In this regard, it is evident that adding more basic capacity might not be useful if maximum utilization of the same is not achieved.

\section{CONCLUSION}

From the study, it was seen that the dwell time has a very big impact toward the capacity of a given facility i.e. the bus stop/ bus bay. When the dwell time is long, few vehicles can be served and vice versa. In this regard, it was noted that, although bus demand is very low during offpeak, the bus stop capacity is also low due to longer dwell times. This is simply because drivers spend more time at the stops waiting for passengers during off-peak times.

Socio-economic activities conducted on the curbside affect the operation of bus stops. These activities prevent smooth movement of passengers from either the bus (alighting) or from the curb. This situation was observed at Mahakama ya ndizi and Ubungo bus bays.

The location of crosswalks was inappropriate at some bus stops observed, since they were located immediately in front of the bus stops. Naturally, this is not safe to the crossing pedestrians because the parked vehicle/bus on the bus bay reduce the visibility of oncoming vehicle.

At Bakhresa bus bay, pedestrians were not considered at all since there is no separation between the passengers, the parked trucks and the buses that require either to pick up or drop off passengers. The stop is not safe to passengers because they have to observe the truck that requires to depart from the parking and also the oncoming bus to pick them up.

On the whole, most bus bay stops possess adequate capacity to cater for the observed demand. In this regard, the results indicate that only $18 \%$ of the bus bay stops studied did not have adequate capacity to cater for the available demand all the time. $9 \%$ did not have adequate capacity during peak hours but the capacity was adequate during off-peak hours. The remaining $73 \%$ of bus bay stops possess adequate capacity all the time (peak and off-peak hours alike).

However, it was observed that, congestion at bus stops is caused mainly by the erratic behavior of drivers and other road users. Drivers at bus stops not only block each other but also they interfere with through traffic on the curb lane. This results into unnecessarily higher dwell times and higher clearance times. In addition, queues form at bus stops causing unnecessary congestion. Nonetheless, some few technical issues, such as inappropriate location of cross walks and effect of downstream traffic signals, were identified.

It is therefore recommended that, for better operation, strict enforcement measures should be stepped up accompanied with stiff penalties to defaulters. Compliance would ensure that all vehicles are parked appropriately to allow smooth movement of the through traffic. This measure should be undertaken while educating the public on the proper and safe road use.

The capacity of Ubungo, Mahakama ya Ndizi and Usalama bus stops was found to be inadequate to cater for the observed demand due to high values of dwell times calculated from the observed data. In this regard, the following measures should be taken in order to reduce the magnitude of dwell time:

- Avoid conducting socio-economic activities such as business, on the curb side at the loading areas since these activities affect the loading time and hence increasing the dwell time

- Fair payment should take place within the bus before it reaches the bus stop point or bus bay to reduce the time the bus spends at the stop

- Congestion within the vehicles also increases the dwell time as the time for alighting of passengers increases. Limiting the number of excess passengers in a bus would alleviate this problem.

The study covered in this paeper investigated the bus bay performance on one of the congested roads in the city of Dar es Salaam. The study was limited to evaluation of current bus bay performance and its impact to the capacity of the case study road network. Subsequently, conclusions and recommendations for improvement were given. By so doing, the study identified areas for future study, which include:

- Further study is required to determine the extra number of buses required due to limiting of number of standees in a bus and its impact on the capacity of the road network

- A study is required to determine the appropriate location of cross walks in the vicinity of bus bays in order to improve pedestrian safety

- Further study is required to determine the effect of traffic signals on the adjacent bus bay stops and propose optimum locations of the stops

\section{REFERENCES}

Gu, W., Y. Li, M.J. Cassidy and J.B. Griswold, 2010. On the capacity of isolated, curbside bus stops. Transport. Res. Part B: Methodol., 45: 714-723. DOI: $10.1016 /$ j.trb.2011.01.001

Ibrahim, M.R., M.B. Karim and F.A. Kidwai, 2008. The effect of digital count-down display on signalised junction performance. Am. J. Applied Sci., 5: 479482. DOI: 10.3844 /ajassp.2008.479.482

Kwami, A.V., Y.X. Kuan and X. Zhi, 2009. Effect of bus bays on capacity of curb lanes. J. Am. Sci., 5: 107-118.

Nakamura, F., T. Yabbe and S. Suzue, 2005. A study on improvement of bus bay design. J. Eastern Asia Society Transport. Stud., 6: 449-456.

TRB, 2000. Highway Capacity Manual. 3rd Edn., Transportation Research Board, Washington D.C.

TRB, 2003. Transit Capacity and Quality of Service Manual. 2nd Edn., Transportation Research Board, Washington D.C., ISBN-10: 0309087767. 